\title{
Review
}

\section{Non-Surgical Sterilization Methods in Male Animals: A Review}

\author{
Haben Fesseha, MVSc, DVM* \\ Department of Veterinary Surgery and Diagnostic Imaging, School of Veterinary Medicine, Wolaita Sodo University, P. O. Box I38, Wolaita Sodo, Ethiopia
}

*Corresponding author

Haben Fesseha, MVSc, DVM

Assistant Professor, Department of Veterinary Surgery and Diagnostic Imaging, School of Veterinary Medicine, Wolaita Sodo University, P. O. Box I38, Wolaita Sodo, Ethiopia;Tel.+251910737790; E-mail: tseyon.h@gmail.com; haben.fesseha@ymail.com

\section{Article information}

Received: November 4 $4^{\text {th }}, 2019$; Revised: November II ${ }^{\text {th }}, 2019$; Accepted: November 16 ${ }^{\text {th }}, 2019$; Published: November I9 ${ }^{\text {th }}$, 2019

\section{Cite this article}

Fesseha H. Non-surgical sterilization methods in male animals: A review. Vet Med Open J. 2019; 4(I): 49-56. doi: I0. I7I40/VMOJ-4-I36

\section{ABSTRACT |}

Non-surgical sterilization technique in animals is an ancient practice and dates back to 7000 BC. Surgical castration in animals has been applied for centuries to control the animal population, advance genetic selection, improve calmness of aggressive animals and mainly to ensure and selectively provide high-quality meat production for human consumption. An ideal method of castration should cause permanent block to spermatogenesis and inhibit androgenetic enzymes with low-cost of treatment and doesn't affect the welfare of the animal. Even if operative methods are the main methods of castration, hormonal castration and chemical castration are also an alternative and equivalent method of sterilization. Over the past years, non-surgical sterilization has found application in male dogs, cats, monkeys, goats, bulls, hamsters and rabbits. Calcium chloride, lactic acid, sodium chloride, chlorhexidine, formalin, zinc tannate, zinc gluconate, glycerol, glucose, ethanol and silver nitrate are commonly used in chemical castration. After intratesticular application, degeneration of seminiferous tubules and Leydig cells, decrease in testosterone and sperm production, testicular atrophy is observed. In this review, the approaches of chemical castration were mentioned in different male animals.

\section{Keywords}

Male animal; Non-surgical sterilization; Castration; Chemicals; Testicle.

\section{INTRODUCTION}

$\mathrm{S}$ urgical castration is the most common method used to sterilize animals which are unsuitable for the genetic pool and also to eliminate masculine behavior. ${ }^{1}$ Veterinarians are still practicing the open surgical method of castration which is the most effective and the only means of sterilization for male animals. Yet, castration by open surgery requires post-operative care to minimize the risk of hemorrhage and infection. Besides, this method has some disadvantages: it is not cost-effective and time-consuming with risk of severe post-surgical complications. ${ }^{2,3}$

In contrast to the surgical method, the challenge has been taken up by different reproductive biologists to develop a method of chemical sterilization, which may be a better alternative to surgical castration, as well as suited for mass-scale sterilization of male domestic animals without post-operative hazards. ${ }^{2,4}$ In addition, over the last decades different chemical agents were tried to bring about castration using inorganic chemicals, immune-contraceptives and hormones including androgen, ${ }^{5}$ progestogens, ${ }^{6}$ androgens plus progestagens ${ }^{7,8}$ and agonists for gonadotrophin releasing hormone $(\mathrm{GnRH}){ }^{9}$

Different researchers have evaluated non-surgical sterilization with injection of various hormones in many species of male animals, but these treatments failed to induce permanent sterility. Immunization techniques have also been used to induce antibodies against gonadotrophins and $\mathrm{GnRH}$ and had indicated that such immunization techniques vary in effectiveness and in duration of azoospermia. Adverse vaccination reactions were also observed as another disadvantage. . $^{10,11}$

Chemical sterilization has found application in some species of male animals such as monkeys, goats, bulls, hamsters, rabbits and dogs. ${ }^{12,13}$ Open wound in surgical castration has always been an infection focus. Hence, researchers over the past years have also 
tried various chemical agents such as danazol, glycerol, lactic acid, ferric chloride and ferrous sulphate, calcium chloride $\left(\mathrm{CaCl}_{2}\right)$, bacillus calmette-guerin (BCG), zinc gluconate (Neutersol) and 20\% hypertonic saline solution for induction of chemosterilization. ${ }^{14}$ However, all these chemical agents, following intratesticular injection had exhibited pain, pyrexia and even severe testicular inflammation (orchitis). Some agents like, cadmium chloride, glycerol, lactic acid had caused selective destruction of testicular tissue ${ }^{15,16}$ with reversible testicular tissue damage. ${ }^{17}$

Even though the chemicals used had an effect on the destruction of testicular tissue, it had also complications and some drawbacks. For instance, in some cases, the interstitial portion of seminiferous tubules had regenerated after an initial phase of testicular atrophy and this had led to secondary male behavior causing management problems of the animals. ${ }^{18}$ Due to such type of complications caused by the use of the aforementioned chemicals, an effective chemosterilizing agent is yet to be established.

An attempt has been made to induce sterilization by intratesticular cadmium chloride injection in male adult stray dogs ${ }^{19}$ and scrub bulls, ${ }^{20,21}$ but the mechanism of action of this chemical agent is still to be explored. A single bilateral intratesticular injection of calcium chloride had resulted in chemosterilization through the generation of free radicals as well as without induction of any general stress response in male Black Bengal goats. ${ }^{13}$ As a result, chemosterilization is cheap, requires small number of staff and has positive effect on meat yield of castrated bulls. Moreover, it can also be used to control increasing population of stray animals such as dogs and monkeys. ${ }^{14,20}$

\section{HISTORICAL BACKGROUND}

History of sterilization of domestic animals dates back to 7000 $\mathrm{BC}$ with professional oversight of the practise being documented from the $15^{\text {th }}$ to $19^{\text {th }}$ centuries and it has been applied for centuries to control the number of animals, genetic selection, tranquillity of aggressive animals and most importantly, to ensure the production of high-quality meat for human needs. ${ }^{22}$ Even if surgical castration has been considered a standard gold tool for sterilization of male animals, several drawbacks have been associated with this procedure such as high cost, time consumption, risk and need for post-operative care and management, small-scale application, requirement of a trained veterinarian and medical equipment. . $^{3,20,23}$

The main methods of castration are surgical castration, hormone inhibition, and chemical castration. ${ }^{22}$ Hormonal castration not only directly affect the target organ but also indirectly affects and damage other organs. Whereas, chemical castration provides an ideal conditions of castration, economic expectations in consideration of the effect in a short time, the animal returns easily to normal physical activities after the process, a small number of person with less skill are required, so this method is more preferred than other methods of castration..$^{14,22}$

Non-surgical chemical sterilization have better advantages over other methods and among these, reduction of pain and stress, elimination of hemorrhage, hernia, infection, myiasis and other surgical sequelae. ${ }^{14,24}$ Accordingly, chemical castration has been suggested as a fast and low-cost alternative which could be used in a wide range of canine populations, especially in poor regions where problem is more intense. ${ }^{25}$ In situ non-invasive approaches such as immune-castration, chemical castration and recently Eugenia caryophyllata essential oil castration minimize post-operative complications and costs associated with surgical castration..$^{23,26}$

Accordingly, several attempts have been made in search of promising effective chemical agent, which included intratesticular injections (ITIs) of a various chemical agents to promote castration in various species such as Rhesus monkey (iron salt), ${ }^{27}$ Rats (Hypertonic saline solution and Calcium chloride), ${ }^{28-31}$ Canine (Calcium chloride, Zinc gluconate, Ethanol, Eugenia caryophyllata essential oil and Glycerol), ${ }^{4,11,15,26,32-34}$ Feline (Calcium chloride, Zinc gluconate), ${ }^{23,35,36}$ Bovine (hypertonic sodium chloride), ${ }^{12,37,38}$ Donkey (Calcium chloride), ${ }^{2}$ Ovine (Formalin) ${ }^{21}$ and Caprine (Calcium chloride and chlorhexidine gluconate \& cetrimide). ${ }^{13,39}$

Similarly, different researches are still being conducted and researchers have been interested in developing a method for chemical castration which might be a better alternative to surgical method. ${ }^{14,20}$ Moreover, surgical method is not effective for largescale application, especially for controlling large population size of undesirable mammals in the community like stray dogs. Besides this, post-operative care and management of the animal were also required to prevent infection. ${ }^{13}$ In addition, vasectomies and vasal occlusion are less invasive surgical procedures than castration, still these procedures also carry similar anesthetic risks and post-surgical complications. ${ }^{2,3}$

An ideal chemical sterilizing agent should be permanent, low-cost treatment, effectively arrests spermatogenesis and androgenesis and not affecting the welfare of animals as well as without side effects. ${ }^{4,14,40}$

\section{CHEMICAL STERILIZATION METHODS IN MALE ANIMALS}

Control of fertility can be achieved through chemical contraceptives which prevents the birth of offspring but maintains fertility. However, by sterilization the animals renders infertile. ${ }^{41,42}$ Contraception in domestic animals including dogs can be achieved through chemical reproductive control and immunological methods, which prevents pregnancy by sterilizing temporarily or permanently. These methods offers a humane and less expensive alternative to surgical sterilization. ${ }^{34,43}$ Chemosterilization methods so far employed include hormonal methods, Immunocontraceptives and inorganic chemo-sterilants.

\section{HORMONAL METHODS}

Steroidal hormones such as progestin, estrogens and androgens administered via oral tablets or by parenteral injections have been used as reproductive inhibitors in owned $\operatorname{dog} \mathrm{s}^{44,45}$ and have the ability to temporarily control the reproduction of dogs. Gonad- 
otrophin-releasing hormone is one of the target site for fertility inhibitors that control the release of the pituitary gonadotrophins, follicle-stimulating hormone (FSH) and luteinizing hormone $(\mathrm{LH}){ }^{46}$

GnRH agonists are also other hormonal methods and are proteins that act like $\mathrm{GnRH}$ and stimulate the production and release of FSH and LH. These methods can postpone puberty in both sexes and can also control the reproductive cycle..$^{45,47,48}$ Among GnRH agonists, deslorelin (Suprelorin ${ }^{\circledR}$, Virbac, Pukete, Hamilton, New Zealand), is used for inhibition of reproduction in male dogs for at least a year in Australia and Europe. ${ }^{46,49}$

Azagly-nafarelin (Gonazon, Intervet International B.V., Amsterdam, The Netherlands) which is another GnRH agonist, has shown to decrease the concentration of testosterone for at least 6-months. ${ }^{50}$ Gonazon is currently approved in the European Union but has not been yet brought into the European Union market. ${ }^{46,51}$

\section{Immunocontraceptives}

Immuno-contraceptive vaccines are another option and work by inducing antibody production against proteins or hormones essential for reproduction (e.g. gonadotrophins and $\mathrm{GnRH}$ ) and therefore it can prevent pregnancy. ${ }^{46,52}$ In contrast to GnRH agnostics, GnRH based vaccines target $\mathrm{GnRH}$ and prevent ovulation and spermatogenesis. Zona pellucida (ZP)-based vaccines inhibit egg-sperm binding and fertilization. These vaccines are commonly used for population control in wildlife species and domestic dog populations..$^{51,53}$

GonaCon $^{\mathrm{TM}}$ is a GnRH-based vaccine which had been registered as a contraceptive for white-tailed deer, horses and feral donkeys in the United States that induce infertility for at least 1-6 years after a single injection. ${ }^{46,54,55}$ In contrast to ZP-based vaccines, GonaCon $^{\mathrm{TM}}$ has not yet been proven effective in dogs since early formulation of GonaCon ${ }^{\mathrm{TM}}$ showed abscesses and draining at the injection site after the injection. ${ }^{52}$

A new formulation of GonaCon ${ }^{\mathrm{TM}}$ has been produced since then and tested in an experimental study carried out on captive dogs in Mexico. ${ }^{52,56}$ This new formulation of GonaCon ${ }^{\mathrm{TM}}$ did not result in abscesses at the injection sites. According to Kisiel's research finding, it had been indicated that immunization techniques vary in effectiveness and in duration of time to cause azoospermia. Adverse vaccination reactions were also observed as another disadvantage of this method. ${ }^{46,48}$

\section{Inorganic Chemosterilants}

An ideal inorganic chemosterilizing agent would be one that effectively arrests spermatogenesis and androgenesis as well as libido with absence of toxic or other side effects. Inorganic chemo-sterilants are simple, easy with less technical ability and cost effective for mass-scale sterilization., ${ }^{2,20,34}$
The low cost, ease of use and cultural acceptance of a sterilization method that does not require removal of the testes make inorganic chemo-sterilants a valuable tool for large-scale sterilization campaigns, particularly in areas lacking clinical facilities or skilled staff. ${ }^{25,41,46,57}$ Thus, chemical castration could be an attractive option for developing countries with limited resources for surgical management programs..$^{58}$

Researchers over the past five decades have also tried various inorganic chemosterilizing agents such as cadmium chloride, ${ }^{16}$ ferric chloride and ferrous sulphate, ${ }^{27}$ Danazol, ${ }^{59} \mathrm{BCG}^{60}{ }^{60}$ glycerol ${ }^{61}$ and lactic acid $^{18}$ for chemical castration by intra testicular injection in laboratory and domestic animals. After intratesticular injection, all these agents exhibited pain, pyrexia and even severe orchitis. ${ }^{20}$

Chemo-sterilizing agents such as cadmium chloride, glycerol and lactic acid caused selective destruction of testicular tissue with reversible testicular tissue damage. ${ }^{15}$ As result, in some cases, the interstitial portion regenerated after an initial phase of testicular atrophy and this led to secondary male behavior, which caused management problems of the animals Due to the above complications caused by the use of aforementioned chemicals, an effective chemosterilizing agent is yet to be established. ${ }^{18,34}$

For the past 10 -years, an attempt has been made to induce sterilization by intratesticular injection of calcium chloride $\left(\mathrm{CaCl}_{2}\right){ }^{2-4,12,30,62}$ Zinc gluconate (Neutersol ${ }^{22,63}$ and $20 \%$ hypertonic saline solution ${ }^{64,65}$ in bull, cat, dog, donkey, goat and albino mice. As indicated above, different chemical agents were tried and used over the past years. Accordingly, sodium chloride, calcium chloride and zinc gluconate were the most commonly used by different researchers and thus research findings regarding the aforementioned chemicals are described as follows.

Sodium chloride solution: Hypertonic saline is a solution easy to administer, easily available and inexpensive. In a study, 20\% hypertonic saline solution was injected bilaterally into the rat testes at different areas with a total amount of about 0.5 to $1 \mathrm{ml}$ in each testis and reported that the coagulation necrosis was observed in all testes. $22,34,64$

Kwak et $\mathrm{al}^{65}$ revealed that severe degenerative changes were seen in testicular seminiferous tubules and massive infiltration of inflammatory immune cells in animals injected with hypertonic saline solution. Additionally, researchers indicated that intratesticular hypertonic saline injection seems to be an alternative method to orchiectomy and surgical castration. However, further analysis and laboratory work would be required to ascertain the potential utility of this approach in dogs. $28,64,65$

In another study, it was suggested that intratesticular injection of $20 \%$ hypertonic saline could be an effective method for non-surgical sterilization of the young male dogs but not adult dogs. ${ }^{22,34}$ Intratesticular injection of $20 \%$ hypertonic saline solution induces coagulative necrosis of leydig cells and seminiferous tubules as well as extensive testicular fibrosis. Based on the observed lesions, to arrest the testicular development and testoster- 
one synthesis to cause sterility, the intratesticular injection should be performed during the first 20-days of life of the calves. Thus, intratesticular injection sodium chloride solution can be used as a viable alternative to surgical orchiectomy in calves. ${ }^{37}$

The use of inorganic chemo-sterilants in male dogs is an attractive option because it removes the disadvantages such as costs of surgical sterilization and post-operative care. ${ }^{45}$ Furthermore, in countries like Romania and Bahamas where surgical castration of male dogs is not culturally accepted, chemical castration offers a reasonable alternative. ${ }^{58,66,67}$

Calcium chloride $\left(\mathrm{CaCl}_{2}\right)$ : Non-surgical male sterilization techniques have been evaluated as a means to avoid the potential health complications, expense, expertise and facilities required for surgical sterilization procedures. Calcium chloride is one of the most promising chemical agent which has been utilized to chemically castrate a variety of species since $1978 .{ }^{68}$ Different species of experimental animals such as rats, dogs, cats, cattle, donkey and buck were used to evaluate the efficacy of calcium chloride as chemosterilizing agent. ${ }^{14,20}$

Calcium chloride causes necrosis, fibrosis and degeneration of seminiferous tubules and Leydig cells following intratesticular injection. As a result, there was reduction in production of spermatozoa, testosterone and sperm counts in a dose-dependent manner. Although calcium chloride did not affect animals' food intake, it changes blood parameters such as blood cortisol due to stress and swelling of the testicles persisted for three weeks following injection and the behavior of the animals returned to normal a month after treatment. ${ }^{2,3}$ More studies are ongoing to standardize and validate formulation, dosage, and administration protocol for calcium chloride. ${ }^{44,46}$

Intratesticular injection of calcium chloride has been applied to a variety of animal species including mice, ${ }^{3,29} \mathrm{dogs},{ }^{3,4,11}$ cats, ${ }^{36}$ goats, ${ }^{13,39}$ bulls ${ }^{12,19,68}$ and donkey, ${ }^{2}$ in a variety of formulations and concentrations. ${ }^{36}$

A single bilateral intratesticular injection of calcium chloride was found to be effective, economical, easy to perform and does not require removal of testis in male cats and dogs. It had caused permanent sterilization and it is free from pain, chronic stress and had been found a simple alternative method to surgical castration..$^{3,36}$

One bilateral intratesticular injection of $20 \%$ calcium chloride in ethyl alcohol solution was optimum for rendering dogs azoospermic and lower testosterone levels by $70 \%$ without side effects. ${ }^{11}$ After single intratesticular injection of calcium chloride, destruction in seminiferous tubules and leydig cells, decrease in testosterone and sperm production, atrophy in testicles were observed. Thus, calcium chloride was effective and can be used as substitution of surgical castration in bull, buck, rat, cat and dog., $14,29,30,36,38,69$

Furthermore, calcium chloride injection has major role on impairing male reproductive organs resulting in sterility together with various key reproductive parameters including testicular histology but other general parameters were intact. ${ }^{69}$

Procedure of intratesticular injection of calcium chloride solutions: each intratesticular injection can be administered using a sterile 21-gauge needle directed from the caudo-ventral aspect of each testis approximately one $\mathrm{cm}$ from the epididymal tail and towards the dorso-cranial aspect of that testis, so that the solution can be deposited over the entire route by linear infiltration while withdrawing the needle from the proximal end to the distal end. All animals should be restrained through a gentle handling and proper care. The intratesticular injections should be given very carefully in order to prevent seepage of the solution from the injection site and avoid any other intramuscular injections. First, the animals can also be restrained through the proper handling procedure in a prior experiment in the case of vaccination and blood collection, etc. The animals should be kept under routine clinical observations and follow-up (Figure 1). 3,14,22

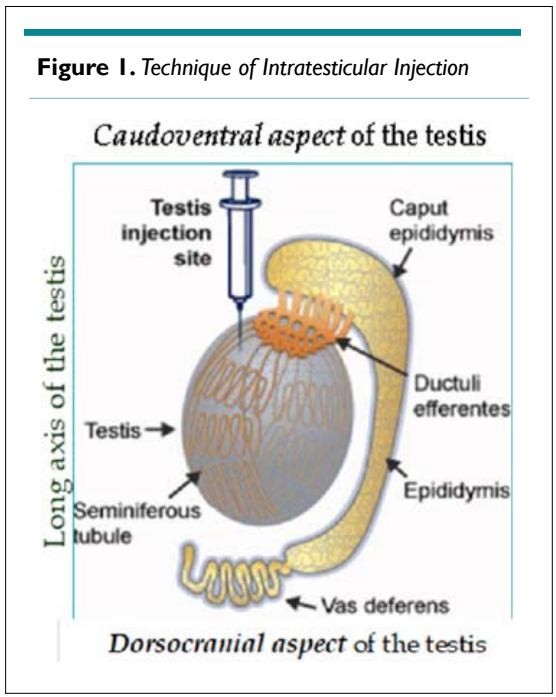

Zinc gluconate neutralized by arginine (Neutersol): Zinc gluconate was the first chemical sterilizing product to fulfil the criteria three key criteria of an ideal method of chemical sterilization. That is, first, effectiveness and large-scale application in male animals. Second, high margin of safety without adverse effects for the environment. Thirdly, it has to be permanent and irreversible following a single treatment. The first product obviously fulfilling these criteria was zinc gluconate. It was first described by Fahim et $\mathrm{al}^{70}$ who injected Neutersol (Pet Healthcare International, Inc., Columbia, MO, USA), a Zinc Gluconate-based chemical sterilant into the epididymis of dogs. It is a zinc-gluconate solution neutralized by arginine to a $\mathrm{pH}$ of 7 . Subsequently, Neutersol was injected into the testes of puppies and in the testes of adult dogs. ${ }^{32,71}$

Zinc gluconate is currently available in Mexico, Colombia, Bolivia, and Panama as Esterilsol and in the United States as Zeuterin (both through Ark Sciences, New York). The cost of Esterisol is about US $\$ 15$ per $\operatorname{dog}$ (medium size). ${ }^{44,46}$ The procedure involves injecting a predetermined amount of zinc solution based 
on scrotal width into each testis of puppies 3-10-months of age. ${ }^{41}$ Histological findings of the testis after injection of Neutersol at the age of 2.5-months revealed almost complete fibrosis of the seminiferous tubules and Leydig cells. ${ }^{41,72}$

Zinc gluconate neutralized by arginine (Neutersol, Addison Biological Laboratory Inc., Fayette, Missouri, USA) was approved in 2003 by the US Food and Drug Administration for chemical sterilization of male puppies. Injected into the testicles, this chemical causes sclerosis of the testes and sterility. Neutersol induced sterilization in $99.6 \%$ of the 223 male puppies aged between 3 to 10 -months. ${ }^{73}$ During intratesticular injection of the chemical, sedation is recommended to prevent movements of the dog. Correct injection technique was found critical for the safe use of $\mathrm{Neutersol}^{\circledR}$ in order to avoid ulceration of the scrotum and painful swelling of the testes. ${ }^{41,71}$

Unlike Neutersol $^{\circledR}$, Esterilsol ${ }^{\circledR}$ is currently used as chemical sterilizing agent in Mexico. However, both products still can't produce a long-lasting decrease in testosterone level that can significantly reduce nuisance and aggressive behavior. Studies using these models of male contraception report no or minimal signs of discomfort have been observed following injection, but a transient increase in testicular diameter may follow the injection, resulting in scrotal swelling. Additional local and systemic reactions reported after intra-testicular injections include scrotal ulceration and dermatitis, scrotal self-mutilation, preputial swelling, vomiting, diarrhea, anorexia, lethargy and leukocytosis. Also, unlike surgical castration, this kind of chemical sterilization does not eliminate gonadal sources of testosterone. ${ }^{36,71,72}$

In 2010, Esterilsol received regulatory approval for use in dogs three months and older in Bolivia, Colombia and Panama after introduced by Ark Sciences as Esterilsol in Mexico in 2008. In Colombia, it is also approved for use in cats. ${ }^{46,57}$

In a study carried out in the Galapagos, Ecuador, severe injection-site reactions occurred in 3.9\% of the 103 dogs treated with zinc gluconate. Initially, the basal testosterone concentration in treated dogs decreased but two years after treatment. The effect was similar to untreated dogs. ${ }^{44,57}$ Thus, secondary male characteristics such as roaming, marking, aggression and mounting may be displayed. ${ }^{46,50}$

A study was carried out with Esterilsol in Mexico and found that this compound induced azoospermia or aspermia in 52 out of 53 dogs when administered a single dose per testis. ${ }^{74}$ The incidence of ulcers in dogs after poor injection technique was higher $(2.6 \%)$ and incidence had decreased after proper injection technique using new needles for each injection. A similar study conducted in Brazil for dogs had concluded that zinc gluconate could be regarded as a permanent sterilant with no observed sign of behavioral alterations or severe discomfort following intratesticular injection. $^{25}$

Another study in Isabela Island, zinc gluconate has got greater social and cultural acceptance as an option for surgical method since this technique provides low cost, ease of use, does not require removal of the testes, large-scale use, particularly in remote locations lacking sophisticated clinical facilities or skilled surgeons and staff. ${ }^{57}$

Esterilsol is administered via an injection to each testicle with either a 28 gauge, $3 / 4$ inch or a 30 gauge, $1 / 2$ inch needle, specified by manufacturer depending on the dose determined for the individual dog. Esterilsol is labeled for use in dogs with an individual testicular width of $10-27 \mathrm{~mm}$. Ark Sciences has recommended light sedation is enough to ensure that the dog holds still during the injection (General anesthesia is not necessary; so, reversible sedation is commonly used so that dogs are awake and alert in as little as 15-20-minutes after the Esterilsol injection/zinc neutering). ${ }^{44}$

Experienced practitioners report that the process of measuring the testicular width (to determine dose), preparing the injections and administering the injection into each testicle takes two to five minutes. Following intratesticular injection, proper follow-up is critical to reduce the risk of injection site reactions. Thus, this formulation was found to cause permanent sterility in $99.6 \%$ of treated dogs. ${ }^{14,44,46}$ Further investigation is needed to identify risk factors for adverse reactions to zinc gluconate and to develop strategies for its avoidance.

\section{CONCLUSION AND RECOMMENDATIONS}

In general, non-surgical methods of sterilizations have greater safety over operative method since each chemical substance has minimal side effects. Besides, it can be preferred for its less postoperative complication, cheap, small number of staff requirements, ease of application and especially positive effect on meat yield in bulls and pigs. In conclusion, non-surgical sterilizations approach and techniques are significant in terms of both animal welfare and cost effectiveness especially in male animals.

\section{ACKNOWLEDGEMENTS}

I would like to express my gratitude and appreciation to my family for their financial and moral support and so much more.

\section{REFERENCES}

1. Auer JA, Stick J. Reproductive System in Equine Surgery. $3^{\text {rd }}$ ed. Philadelphia,USA: Saunders Elsevier; 2006: 282-295.

2. Ibrahim A, Ali MM, Abou-Khalil NS, Ali MF. Evaluation of chemical castration with calcium chloride versus surgical castration in donkeys: Testosterone as an endpoint marker. BMC Vet Res. 2016; 12(1): 46. doi: 10.1186/s12917-016-0670-3

3. Jana K, Samanta PK. Sterilization of male stray dogs with a single intratesticular injection of calcium chloride: A dose-dependent study. Contraception. 2007; 75(5): 390-400. doi: 10.1016/j.contraception.2007.01.022 
4. Leoci R, Aiudi G, Silvestre F, Lissner EA, Marino F, Lacalandra GM. A dose-finding, long-term study on the use of calcium chloride in saline solution as a method of nonsurgical sterilization in dogs: Evaluation of the most effective concentration with the lowest risk. Acta Vet Scand. 2014; 56(1): 63. doi: 10.1186/s13028-0140063-1

5. Matsumoto AM. Is high dosage testosterone an effective male contraceptive agent? Fertil Steril. 1988; 50(2): 324-328. doi: 10.1016/ S0015-0282(16)60081-X

6. Swerdloff R, Wang C, Bhasin S. Developments in the control of testicular function. Baillieres Clin Endocrinol Metab. 1992; 6(2): 451483. doi: 10.1016/s0950-351x(05)80158-2

7. Dube D, Assaf A, Pelletier G, Labrie F. Morphological study of the effects of an $\mathrm{GnRH}$ agonist on the canine testis after four months of treatment and recovery. Acta Endocrinol (Copenh). 1987; 116(3): 413-417. doi: 10.1530/acta.0.1160413

8. Wu FC, Aitken RJ. Suppression of sperm function by depot medroxyprogesterone acetate and testosterone enanthate in steroid male contraception. Fertil Steril. 1989; 51(4): 691-698. doi: 10.1016/ s0015-0282(16)60623-4

9. Tremblay Y, Bélanger A. Reversible inhibition of gonadal functions by a potent gonadotropin-releasing hormone agonist in adult dog. Contraception. 1984; 30(5): 483-497. doi: 10.1016/00107824(84)90039-8

10. Gonzalez A, Allen A, Post K, Mapletoft R, Murphy B. Immunological approaches to contraception in dogs. J Reprod Fertil Suppl. 1989; 39: 189-198.

11. Leoci R, Aiudi G, Silvestre F, Lissner EA, Lacalandra GM. Alcohol diluent provides the optimal formulation for calcium chloride non-surgical sterilization in dogs. Acta Vet Scand. 2014; 56(1): 62. doi: 10.1186/s13028-014-0062-2

12. Canpolat I, Gur S, Gunay C, Bulut S, Eroksuz H. An evaluation of the outcome of bull castration by intra-testicular injection of ethanol and calcium chloride. Revue de Médecine Vétérinaire. 2006; 157(8/9): 420.

13. Jana K, Samanta P, Ghosh D. Evaluation of single intratesticular injection of calcium chloride for nonsurgical sterilization of male Black Bengal goats (Capra hircus): A dose-dependent study. Anim Reprod Sci. 2005; 86(1-2): 89-108. doi: 10.1016/j.anireprosci.2004.05.021

14. Hassan A, Fromsa A. Review on chemical sterilization of male dogs. Int J Adv Res. 2017; 5(11): 758-770. doi: 10.21474/ IJAR01/5828

15. Immegart HM, Threlfall WR. Evaluation of intratesticular injection of glycerol for nonsurgical sterilization of dogs. Am J Vet Res.. 2000; 61(5): 544-549. doi: 10.2460/ajvr.2000.61.544
16. Pařizek J. The third oliver bird lecture sterilization of the male by Cadmium salts. Reproduction. 1960; 1(3): 294-309.

17. Heath E, Arowolo R. The early histopathologic effects of intratesticular injection with hyperosmolar glycerol, glucose or $\mathrm{NaCl}$ solutions. Andrologia. 1987; 19(6): 654-661. doi: 10.1111/j.14390272.1987.tb01922.x

18. Fordyce G, Hodge PB, Beaman NJ, Laing AR, Campero C, Shepherd RK. An evaluation of calf castration by intra-testicular injection of a lactic acid solution. Aust Vet J. 1989; 66: 272-276. doi: 10.1111/j.1751-0813.1989.tb13950.x

19. Mitra B, Samanta P. Testicular degeneration of scrub bulls by calcium chloride. Indian J Vet Sur. 2000; 21(1): 37-38.

20. Alper B, İbrahim C. Chemical sterilization in domestic animals. Research in Agricultural and Veterinary Sciences. 2019; 3(1): 5-9.

21. Ijaz A, Abalkhail A, Khamas W. Effect of intra testicular injection of formalin on seminiferous tubules in Awassi lambs. Pakistan Vet J. 2000; 20(3): 129-134.

22. Cavalieri J. Chemical sterilisation of animals: A review of the use of zinc-and $\mathrm{CaCl}_{2}$ based solutions in male and female animals and factors likely to improve responses to treatment. Anim Reprod Sci. 2017; 181: 1-8. doi: 10.1016/j.anireprosci.2017.03.010

23. Fagundes AKF, Oliveira EC, Tenorio BM, Melo CC, Nery LT, Santos FAB, et al. Injection of chemical castration agent, zinc gluconate, into the testes of cats results in the impairment of spermatogenesis: A potentially irreversible contraceptive approach for this species. Theriogenology. 2014; 81(2): 230-236. doi: 10.1016/j.theriogenology.2013.09.013

24. Cohen RDH, King BD, Thomas LR, Janzen ED. Efficacy and stress of chemical versus surgical castration of cattle. Canadian J Anim Sci. 1990; 70(4): 1063-1072.

25. Soto FRM, Viana WG, Sousa A, et al. Evaluation of zinc gluconate, either associated or not to dimethyl sulfoxide, as contraceptive method for male dogs. Anim Reprod. 2007; 4: 119-124.

26. Abshenas J, Molaei MM, Derakhshnfar A, Ghalekhani N. Chemical Ssterilization by intratesticular injection of eugenia caryophyllata essential oil in dog: A histopathological study. Iranian J Vet Surg. 2013; 8(2): 9-16.

27. Kar AB, Kamboj V, Goswami A. Sterilization of male rhesus monkeys by iron salts. J Reprod Fertil. 1965; 9(1): 115-117. doi: 10.1530/jrf.0.0090115

28. Emir L, Sunay M, Yalbuzdağ O, Karakaya Y, Erol D. Hormonal and pathologic changes after chemoablation of testes with hypertonic saline solution as a treatment method alternative to orchiectomy in patients with hormone sensitive metastatic prostatic cancer. Urol Oncol. 2011; 29(2): 212-217. doi: 10.1016/j. 
urolonc.2008.12.021

29. Jana K, Samanta P, Ghosh D. Dose-dependent response to an intratesticular injection of calcium chloride for induction of chemosterilization in adult albino rats. Vet Res Commun. 2002; $26(8)$ : 651-673. doi: 10.1023/a:1020976905746

30. Jana K, Samanta PK. Evaluation of single intratesticular injection of calcium chloride for nonsurgical sterilization in adult albino rats. Contraception. 2006; 73(3): 289-300. doi: 10.1016/j.contraception.2005.07.011

31. Nishimura N, Kawate N, Sawada T. Chemical castration by a single intratesticular injection of lactic acid in rats and dogs. $J$ Reprod Develop. 1992; 38: 263-266. doi: 10.1262/jrd.38.263

32. Oliveira EC, Moura MRP, de Sá MJ, et al. Permanent contraception of dogs induced with intratesticular injection of a zinc gluconate-based solution. Theriogenology. 2012; 77(6): 1056-1063. doi: 10.1016/j.theriogenology.2011.10.008

33. Pineda M, Reimers T, Faulkner L, Hopwood M, Seidel JG. Azoospermia in dogs induced by injection of sclerosing agents into the caudae of the epididymides. Am J Vet Res. 1977; 38(6): 831-838.

34. Canpolat I, Karabulut E, Eröksüz Y. Chemical castration of adult and non-adult male dogs with sodium chloride solution. Journal of Agriculture and Veterinary Science. 2016; 9(12): 9-11. doi: 10.9790/2380-0912010911

35. Pineda M, Dooley MP. Surgical and chemical vasectomy in the cat. Am J Vet Res. 1984; 45(2): 291-300.

36. Jana K, Samanta PK. Clinical evaluation of non-surgical sterilization of male cats with single intra-testicular injection of calcium chloride. BMC Vet Res. 2011; 7: 39. doi: 10.1186/1746-6148-7-39

37. Neto OA, Gasperin BG, Rovani MT, et al. Intratesticular hypertonic sodium chloride solution treatment as a method of chemical castration in cattle. Theriogenology. 2014; 82(7): 1007-1011. e1. doi: 10.1016/j.theriogenology.2014.07.020

38. Capucille DJ, Poore MH, Rogers GM. Castration in cattle: Techniques and animal welfare issues. Compendium. 2002; 24: 66-73.

39. Mohammed A, James FO. Chemical castration by a single bilateral intra-testicular injection of chlorhexidine gluconate and cetrimide in bucks. Sokoto J Vet Sci. 2013; 11(1): 62-65. doi: 10.4314/ sokjvs.v11i1.10

40. Wiebe JP, Barr KJ, Buckingham KD. Sustained azoospermia in squirrel monkey, Saimiri sciureus, resulting from a single intratesticular glycerol injection. Contraception. 1989; 39(4): 447-457. doi: 10.1016/0010-7824(89)90122-4

41. Kutzler M, Wood A. Non-surgical methods of contraception and sterilization. Theriogenology. 2006; 66(3): 514-525. doi: 10.1016/j. theriogenology.2006.04.014

42. Munson L. Contraception in felids. Theriogenology. 2006; 66(1): 126-134. doi: 10.1016/j.theriogenology.2006.03.016

43. FAO. Dog Population Management FAO/WSPA/IZSAM Expert meeting. Paper presented at: Food and Agriculture Organization of the United Nations; 2011; Banna, Italy.

44. Alliance for Contraception in Cats and Dogs (ACC\&D). Contraception and fertility control in dogs and cats. Web site. https:// www.acc-d.org/. 2013. Accessed November 3, 2019.

45. Rojas MAM, Rodríguez IMV, Tovar DS. Métodos para el control de poblaciones caninas: Una introducción [In: Spanish]. Una Salud. 2011; 2 (1): 63-79.

46. Massei G, Miller LA. Nonsurgical fertility control for managing free-roaming dog populations: A review of products and criteria for field applications. Theriogenology. 2013; 80(8): 829-838. doi: 10.1016/j.theriogenology.2013.07.016

47. Romagnoli S, Stelletta C, Milani C, Gelli D, Falomo M, Mollo A. Clinical use of deslorelin for the control of reproduction in the bitch. Reprod Domest Anim. 2009; 44: 36-39. doi: 10.1111/j.14390531.2009.01441.x

48. Kisiel LM. Using a Dog Demography Field Study to Inform the Development of an Agent-based Computer Simulation. Evaluating Owned Dog Population Control Interventions in a Small, Semi-urban Community im Mexico. [master's thesis]. Ontario, Canada: University of Guelph; 2017.

49. Trigg T, Wright P, Armour A, et al. Use of a GnRH analogue implant to produce reversible long-term suppression of reproductive function in male and female domestic dogs. I Reprod Fertil Suppl. 2001; 57: 255-261.

50. Goericke-Pesch S, Wilhelm E, Ludwig C, Desmoulins P, Driancourt M, Hoffmann B. Evaluation of the clinical efficacy of Gonazon implants in the treatment of reproductive pathologies, behavioral problems, and suppression of reproductive function in the male dog. Theriogenology. 2010; 73(7): 920-926. doi: 10.1016/j. theriogenology.2009.11.018

51. Ajadi T, Oyeyemi M. Short-term effects of a single dose of gonadotrophin releasing hormone $(\mathrm{GNRH})$ vaccine on testicular and ejaculate characteristics of dogs. Bulgarian J Vet Med. 2015; 18: 123-131. doi: $10.15547 /$ bjvm.809

52. McLaughlin E, Aitken R. Is there a role for immunocontraception? Mol Cell Endocrinol. 2011; 335(1): 78-88. doi: 10.1016/j. mce.2010.04.004

53. Miller LA, Fagerstone KA, Wagner DC, Killian GJ. Factors contributing to the success of a single-shot, multiyear PZP immunocontraceptive vaccine for white-tailed deer. Human-Wildlife 
Conflicts. 2009; 3(1): 103-115. doi: 10.26077/man3-ra98

54. Killian G, Thain D, Diehl NK, Rhyan J, Miller L. Four-year contraception rates of mares treated with single-injection porcine zona pellucida and GnRH vaccines and intrauterine devices. Wildlife Research. 2008; 35(6): 531-539. doi: 10.1071/WR07134

55. Miller LA, Gionfriddo JP, Fagerstone KA, Rhyan JC, Killian GJ. The single-shot $\mathrm{GnRH}$ immunocontraceptive vaccine (GonaCon ${ }^{\text {TM}}$ ) in white-tailed deer: Comparison of several GnRH preparations. Am J Reprod Immunol. 2008; 60(3): 214-223. doi: 10.1111/j.1600-0897.2008.00616.x

56. Vargas-Pino F, Gutiérrez-Cedillo V, Canales-Vargas EJ, et al. Concomitant administration of GonaCon ${ }^{\mathrm{TM}}$ and rabies vaccine in female dogs (Canis familiaris) in Mexico. Vaccine. 2013; 31(40): 4442-4447. doi: 10.1016/j.vaccine.2013.06.061

57. Levy JK, Crawford PC, Appel LD, Clifford EL. Comparison of intratesticular injection of zinc gluconate versus surgical castration to sterilize male dogs. Am J Vet Res. 2008; 69(1): 140-143. doi: 10.2460/ajvr.69.1.140

58. Garde E, Pérez G, Vanderstichel R, Dalla Villa P, Serpell J. Effects of surgical and chemical sterilization on the behavior of freeroaming male dogs in Puerto Natales, Chile. Prev Vet Med. 2016; 123: 106-120. doi: 10.1016/j.prevetmed.2015.11.011

59. Dixit V, Lohiya N, Arya M, Agrawal M. Chemical sterilization of male dogs after a single intra-testicular injection of "Danazol". Folia Biologica. 1975; 23(3): 305-310.

60. Naz RK, Talwar GP. Immunological sterilization of male dogs by BCG. Int J Androl. 1981; 4(1-6): 111-128. doi: 10.1111/j.13652605.1981.tb00697.x

61. Wiebe JP, Barr KJ. The control of male fertility by 1, 2, 3-trihydroxypropane (THP; glycerol): Rapid arrest of spermatogenesis without altering libido, accessory organs, gonadal steroidogenesis, and serum testosterone, LH and FSH. Contraception. 1984; 29(3): 291-302. doi: 10.1016/s0010-7824(84)80009-8

62. Alliance for Contraception in Cats and Dogs (ACC\&D). Calcium Chloride as a non-surgical sterilant for male dogs and cats: A History and Summary of Research. Web site. https://www.acc-d. org/docs/default-source/Research-and-Innovation/accd_cacl2review-nov2014.pdf?sfvrsn=2. Accessed November 3, 2019.

63. National Anti-Doping Agency (NADA). Freedom of information summary. Web site. https://animaldrugsatfda.fda.gov/adafda/app/search/public/document/downloadFoi/748. Accessed November 3, 2019.
64. Emir L, Dadalı M, Sunay M, Erol D, Çaydere M, Üstün H. Chemical castration with intratesticular injection of $20 \%$ hypertonic saline: A minimally invasive method. Urol Oncol. 2008; 26(4): 392-396. doi: 10.1016/j.urolonc.2007.05.013

65. Kwak BK, Lee SH. Intratesticular injection of hypertonic saline: Non-invasive alternative method for animal castration model. Dev Reprod. 2013; 17(4): 435-440. doi: 10.12717/DR.2013.17.4.435

66. Cocia RI, Rusu AS. Attitudes of Romanian pet caretakers towards sterilization of their animals: Gender conflict over male, but not female, companion animals. Anthrozoös. 2010; 23(2): 185-191. doi: 10.2752/175303710X12682332910097

67. Fielding WJ, Samuels D, Mather J. Attitudes and actions of West Indian dog owners towards neutering their animals: A gender issue? Anthrozoös. 2002; 15(3): 206-226. doi: $10.2752 / 089279302786992487$

68. Koger L. Calcium chloride castration. Mod Vet Pract. 1978; 59(2): 119-121.

69. Karmakar SN, Das SK. Chemosterilization induced by intratesticular injection of calcium chloride $\left(\mathrm{CaCl}_{2}\right)$-a tool for population control. International Journal of Pharmaceutical, Chemical and Biological Sciences. 2017; 7(1): 25-35.

70. Fahim M, Wang M, Sutcu M. Sterilization of dogs with intraepididymal injection of zinc arginine. Contraception. 1993; 47: 107122. doi: 10.1016/0010-7824(93)90113-1

71. Oliveira EC, Fagundes AK, Melo CC, et al. Intratesticular injection of a zinc-based solution for contraception of domestic cats: A randomized clinical trial of efficacy and safety. Vet J. 2013; 197(2): 307-310. doi: 10.1016/j.tvj1.2013.01.011

72. Tepsumethanon V, Wilde H, Hemachudha T. Intratesticular injection of a balanced zinc solution for permanent sterilization of dogs. Journal of Medical Association Thailand. 2005; 88: 686-689.

73. Wang M. Neutersol: Intratesticular injection induces sterility in dogs. Paper presented at: $1^{\text {st }}$ ACC\&D International Symposium on Non-surgical Methods for Pet Population Control; 2002; OR, USA.

74. Esquivel LC. Evaluation of a single intratesticular injection of zinc gluconate neutralized by Arginine (Neutersol $\mathbb{R})$ as a chemical sterilant in sexually mature, male dogs. Paper presented at: $3^{\text {rd }}$ ACC\&D International Symposium on Non-surgical contraceptive methods for Pet Population Control; 2006; Virginia, USA. 